\title{
UNIDADES DE CONSERVAÇÃO DO MUNICÍPIO DE GUARULHOS: AVALIAÇÃO COM BASE EM ASPECTOS GEOAMBIENTAIS E INSTRUMENTOS DE GESTÃO
}

\author{
CONSERVATION AREAS OF THE GUARULHOS COUNTY: ASSESMENT BASED \\ ON GEOENVIRONMENTAL ASPECTS AND MANAGEMENT TOOLS
}

\author{
ÁREAS DE CONSERVACIÓN DEL MUNICIPIO DE GUARULHOS: EVALUACIÓN \\ BASADA EN ASPECTOS GEOAMBIENTALES Y HERRAMIENTAS DE GESTIÓN
}

\author{
Silmara Guerra Ferraz da Fonseca - Universidade de Guarulhos - Guarulhos - São Paulo - Brasil \\ guerra.silmara@gmail.com
Marcio Roberto Magalhães de Andrade - Universidade de Guarulhos - Guarulhos - São Paulo - Brasil mmandrade@prof.ung.br \\ Antonio Manoel dos Santos Oliveira - Universidade de Guarulhos - Guarulhos - São Paulo - Brasil \\ aoliveira@prof.ung.br
}

\begin{abstract}
Resumo
0 município de Guarulhos integra a Região Metropolitana de São Paulo que é abrangida e envolvida pela Reserva da Biosfera do Cinturão Verde da Cidade de São Paulo (RBCV). Nesse contexto, Guarulhos tem um papel estratégico ao apresentar um total de nove Unidades de Conservação da Natureza, espaços territoriais especialmente protegidos que se estendem por uma área equivalente a $42,4 \%$ do território do município. Estas Unidades de Conservação concentram-se notadamente na região norte de Guarulhos, em terrenos relacionados ao Planalto Mantiqueira, uma região formada por relevo serrano intermediada por morros, em oposição à região sul relacionada ao Planalto de São Paulo, onde o relevo colinoso inclui amplas planícies fluviais apresentando intensa ocupação do solo. Dessa forma, as características geoambientais observadas nestas Unidades de Conservação indicam uma clara vocação para serviços ambientais que garantem a manutenção da cidade e região. Este artigo estabelece uma proposta de avaliação das Unidades de Conservação de Guarulhos com base em aspectos geoambientais e instrumentos de gestão.
\end{abstract}

Palavras-chave: unidades de conservação, Guarulhos, geoambiental, gestão.

\section{Abstract}

The Guarulhos County is situated within the São Paulo Metropolitan Region which is comprised and surrounded by the Biosphere Reserve of São Paulo City Green Belt. In this context Guarulhos has a strategic role since there is a total of nine Nature Conservation Areas within its boundary. These Conservation Areas are special protected territories and extend to $42,4 \%$ of the Guarulhos County extent. The Conservation Areas are notably concentrated at the northern of Guarulhos on uplands of Mantiqueira. This landscape contrasts with the Guarulhos southern where the contour is hilly and comprises extensive alluvial plain presenting intensive land use. Thus the geoenvironmental features presented by these Conservation Areas indicate a clear vocation for environmental services that should ensure the maintenance of the Guarulhos City and its surroundings. This paper sets out a proposal for assessment of the Guarulhos Conservation Units based on their geoenvironmental features and instruments of management.

Key words: conservation areas, Guarulhos, geoenvironmental, management. 
Resumen

El municipio de Guarulhos integra la Región Metropolitana de São Paulo, inclusa en la Reserva de la Biosfera del Cinturón Verde de São Paulo (RBCV). En este contexto, Guarulhos tiene un papel estratégico por proporcionar un total de nueve unidades de conservación de la naturaleza, áreas especialmente protegidas que se extienden sobre un área equivalente al $42,4 \%$ del área del municipio. Estas áreas protegidas se concentran principalmente en la región norte de Guarulhos en tierra relacionadas en la Sierra de la Mantiqueira. En oposición en el sur ocurre la meseta de São Paulo, donde el terreno es de colinas com extensas llanuras fluviales y intenso uso de la tierra. Por lo tanto, las características geoambientales observadas en estas áreas protegidas indican una clara vocación de servicios ambientales que garanticen la sostenibilidad de la ciudad y de la región. En este trabajo se presenta una propuesta para la evaluación de las Unidades de Conservación de Guarulhos basada en aspectos geoambientales y herramientas de gestión.

Palabras clave: unidades de conservación, Guarulhos, geoambiental, gestión.

Introdução

As Unidades de Conservação (UCs) no Brasil são áreas representativas sob o ponto de vista da proteção dos ecossistemas e das paisagens notáveis, correspondendo a espaços protegidos por lei e demarcados no território, com o objetivo de garantir a preservação dessas áreas que, muitas vezes, contêm atributos históricos, culturais e étnicos significativos para a sociedade.

O município de Guarulhos participa do cinturão verde ao redor da Região Metropolitana de São Paulo (RMSP) que, segundo Rodrigues, Victor e Pires (2006), configura a Reserva da Biosfera do Cinturão Verde da Cidade de São Paulo (RBCV) . Esta reserva revela-se um verdadeiro recurso estratégico para a manutenção de serviços ecossistêmicos fundamentais para a qualidade ambiental do meio urbano, como é na produção de água para o abastecimento em bacias de mananciais, bem como na regulação de processos microclimáticos e hidrodinâmicos, tão importantes para a saúde pública e segurança social. A implantação de UCs como medida de proteção do cinturão verde de São Paulo é um instrumento efetivo de gestão ambiental que fortalece a resistência às tendências notáveis de pressão pelo uso urbano do solo e pela redução de áreas naturais.

O desempenho ou cumprimento das funções de uma UC pode ser avaliado por diversos fatores ambientais. Em relação ao meio físico, uma UC desempenha tanto mais sua função quanto maior e quanto mais protege a fragilidade geoambiental da área ou sua suscetibilidade a processos geológicos, também quanto à sua inserção em unidades geomorfológicas consistentes, como uma bacia hidrográfica. 
Em relação ao meio biótico, seu desempenho pode ser medido, por exemplo, por sua integridade, biodiversidade e expressão excepcional como exemplar raro.

Quanto ao meio antrópico, a UC tem maior ou menor desempenho, tendo em vista os serviços ecossistêmicos que mantém, favorecendo o bem-estar humano, ou seja, na proximidade com áreas atenuando ilhas de calor urbanas, sua acessibilidade a estudos, pesquisas, atividades culturais e de lazer, seu papel como provedora e protetora de recursos hídricos locais etc.

Entretanto, se todos esses aspectos ambientais não estiverem gestados, o desempenho pode ser reduzido. Assim, aos fatores ambientais devem ser acrescentados os relativos à gestão da UC, que implicam o seu desempenho, correspondem à fundamentação legal e se está adequada ou não; ao plano de manejo, se existe e está em vigor; à gestão, se possui conselho deliberativo e/ou consultivo. Em resumo, o Índice de Desempenho das UCs (IDUC) é função de fatores ambientais (a) e de gestão (g) da seguinte forma: $I D U C=f(a ; g)$.

O presente artigo propõe um índice que contém os fatores mais importantes da avaliação do desempenho das UCs.

\section{Objetivo}

O objetivo deste trabalho é avaliar o desempenho ambiental das UCs do município de Guarulhos/SP com uma proposta de produzir e associar índices básicos que relacionam a fragilidade geoambiental com a cobertura das áreas preservadas com floresta nativa e a efetivação dos instrumentos de gestão obrigatórios por lei. Dessa forma, pretende-se colaborar com a gestão dessas UCs por meio de um diagnóstico básico e uma proposta de nota de avaliação elaborada através de um indicador sintético: o Índice de Desempenho das Unidades de Conservação (IDUC).

\section{Área de estudo}

O município de Guarulhos está localizado no Estado de São Paulo e inserido no quarto maior aglomerado urbano do planeta, a Região Metropolitana de São Paulo (RMSP). A Figura 1 apresenta a localização desse município no continente sul-americano, e demais unidades administrativas. 


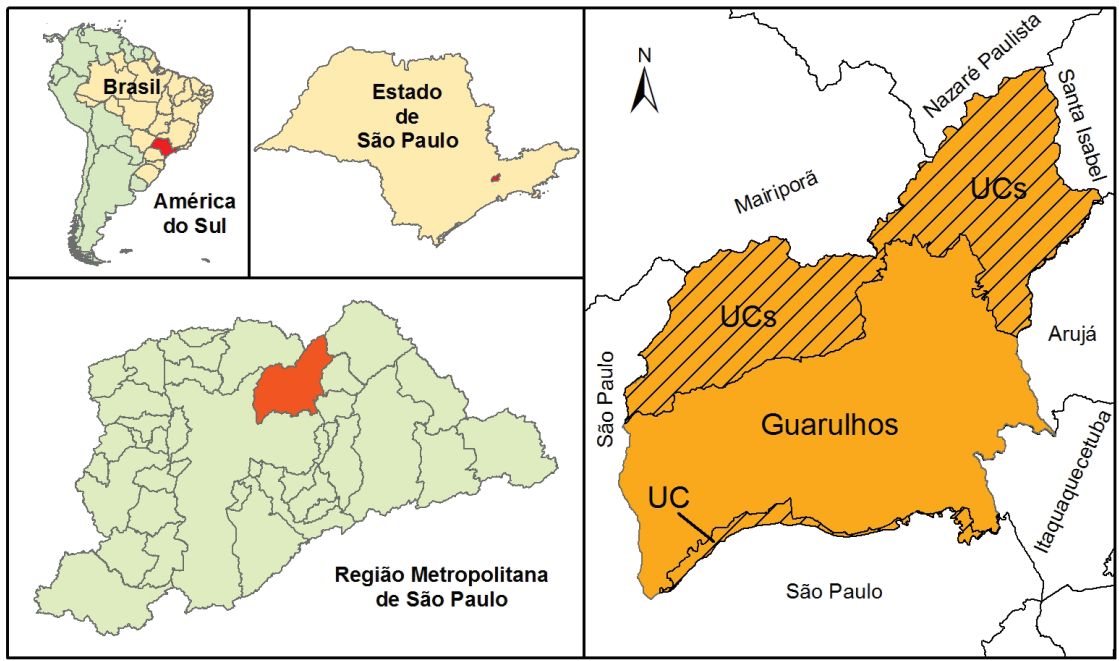

Figura 1: Localização do município de Guarulhos em relação à América do Sul, ao Brasil, ao Estado de São Paulo e à RMSP. Em destaque, as UCs estudadas (hachurado) no território de Guarulhos.

Guarulhos tem destaque regional por corresponder a uma das mais fortes economias do Estado de São Paulo. Pesquisas revelam que seu Produto Interno Bruto (PIB), em 2008, encontrava-se atrás apenas do município de São Paulo (IBGE, 2009); da mesma forma, com seus 1.221.980 habitantes (IBGE, 2010) é a segunda cidade mais populosa do Estado de São Paulo.

Essas expressivas grandezas demográficas e econômicas revelam o extremo vigor nos fluxos humanos, no crescimento urbano, no comércio, na indústria e nos serviços, produzindo uma forte pressão sobre a ocupação territorial da região que se reflete sobre os espaços especialmente protegidos.

A ocupação do território em Guarulhos demonstra uma marcada diferenciação espacial que acompanha, por um lado, a forte periferização da capital paulista e, por outro, uma distribuição urbana que privilegia a ocupação em terrenos de topografia suave. Assim, praticamente toda a ocupação urbana se estabeleceu na porção sul do território, nas terras onde predominam colinas e planícies com topografia mais favorável, em virtude da sua formação geológica sedimentar. 
Além disso, na região norte de Guarulhos, formada por terras elevadas onde predominam morros e serras de rochas cristalinas, a ocupação é mínima e o relevo é coberto por amplos remanescentes de florestas, local onde se encontra a maioria das UCs de Guarulhos. O modelo digital do relevo dessa região e as respectivas UCs (Figura 2) revelam esse contraste topográfico evidente entre as regiões norte e sul.

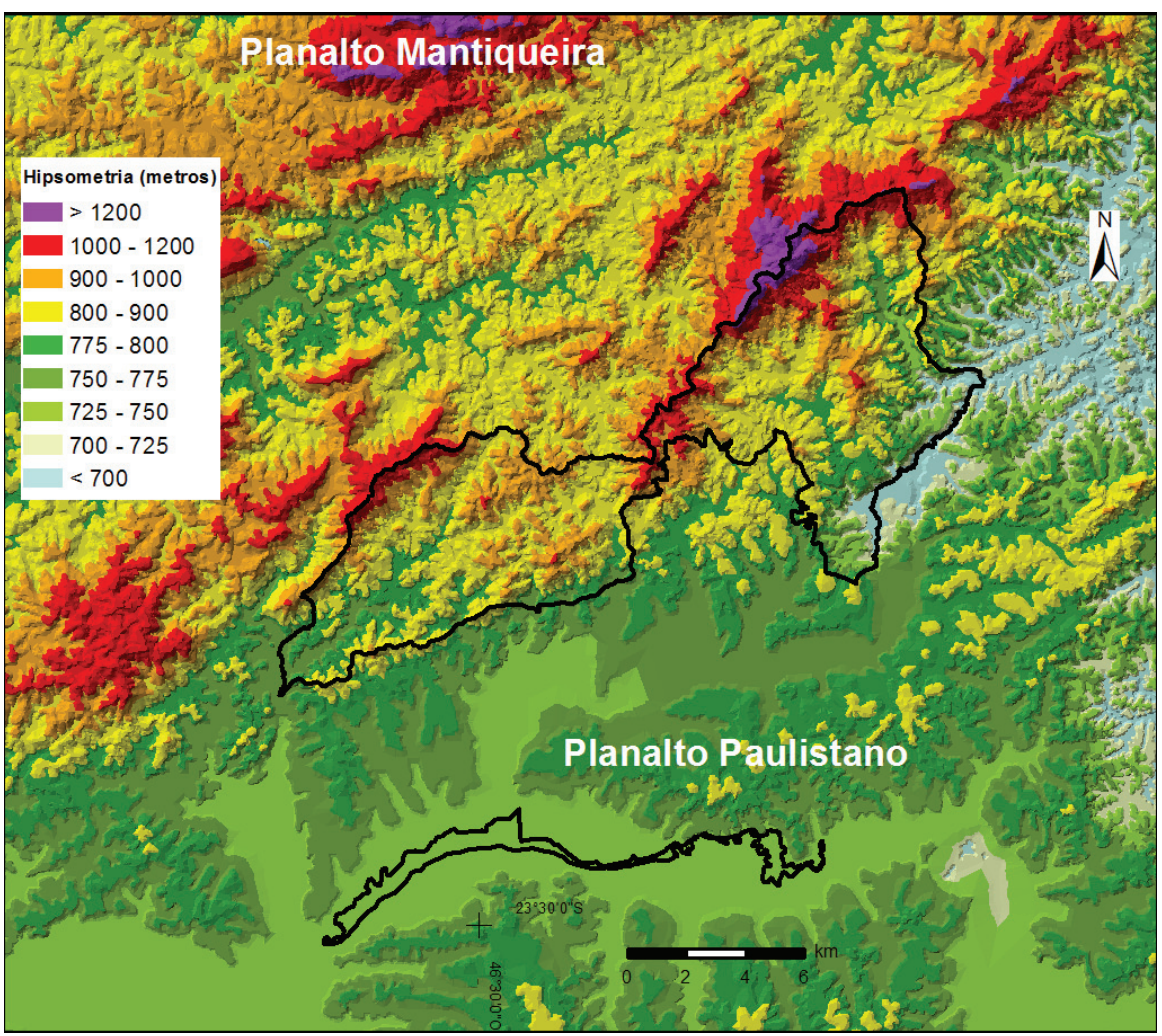

Figura 2: Modelo digital do relevo da região de Guarulhos para a observação das áreas de UCs estudadas no município de Guarulhos e apresentadas na Figura 1.

Com o objetivo de manter e proteger áreas naturais ainda existentes na região, foram criadas um total de nove UCs em Guarulhos que podem ser observadas na Figura 3. 


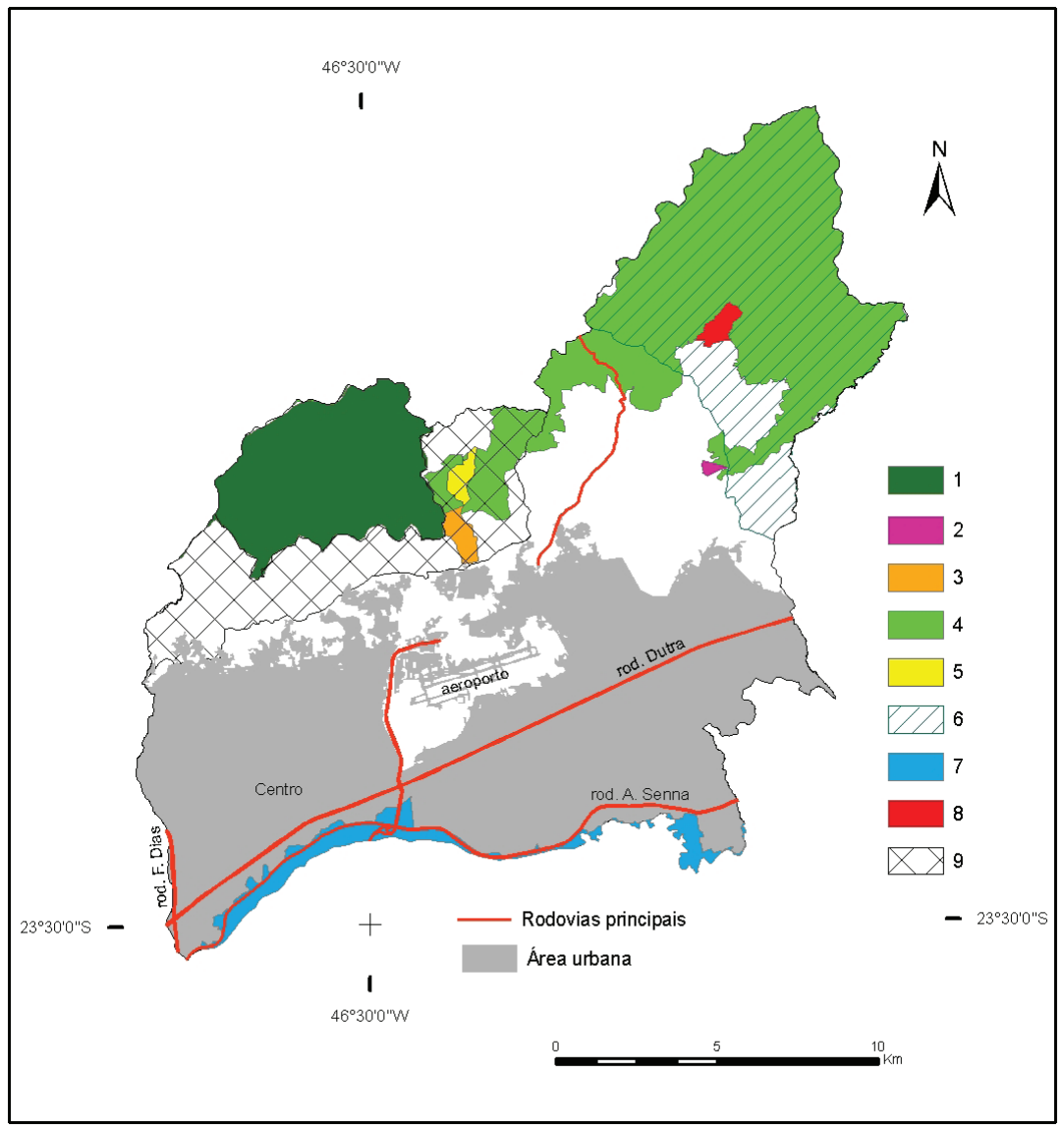

Legenda: 1- Parque Estadual da Cantareira; 2- Reserva Biológica Burle Marx; 3- Parque Natural Municipal da Cultura Negra Sítio da Candinha; 4- Parque Estadual do Itaberaba; 5- Estação Ecológica do Tanque Grande; 6- APA do Rio Paraíba do Sul; 7- APA da Várzea do Rio Tietê; 8- Floresta Estadual de Guarulhos; 9- APA Cabuçu-Tanque Grande.

Figura 3: Mapa das UCs do município de Guarulhos.

Essas UCs foram criadas ao longo do tempo, muitas delas antecedendo a promulgação do Sistema Nacional das Unidades de Conservação (SNUC), pelas esferas públicas Federal, Estadual e Municipal, conforme apresentado no Quadro 1. 
Quadro 1: Unidades de Conservação de Guarulhos, com base no SNUC instituído pela Lei Federal n. 9.985 de 18 de julho de 2000.

\begin{tabular}{|c|c|c|}
\hline Grupos & $\begin{array}{l}\text { Categoria e denominação da unidade de } \\
\text { conservação }\end{array}$ & $\begin{array}{l}\text { Ano de } \\
\text { criação }\end{array}$ \\
\hline \multirow{5}{*}{$\begin{array}{c}\text { Unidade de } \\
\text { conservação de } \\
\text { proteção integral } \\
\text { Artigo } 8^{\circ}\end{array}$} & Parque Estadual da Cantareira ${ }^{2}$ & 1963 \\
\hline & Reserva Biológica Burle Marx ${ }^{1}$ & 1990 \\
\hline & $\begin{array}{l}\text { Parque Natural Municipal da Cultura Negra } \\
\text { Sítio da Candinha }^{1}\end{array}$ & 2008 \\
\hline & Parque Estadual do Itaberaba ${ }^{2}$ & 2010 \\
\hline & Estação Ecológica do Tanque Grande ${ }^{1}$ & 2010 \\
\hline \multirow{4}{*}{$\begin{array}{c}\text { Unidade de } \\
\text { conservação de uso } \\
\text { sustentável } \\
\text { Artigo } 14\end{array}$} & Área de Proteção Ambiental do Paraíba do Sul ${ }^{3}$ & 1982 \\
\hline & $\begin{array}{l}\text { Área de Proteção Ambiental da Várzea do Rio } \\
\text { Tietê }{ }^{2}\end{array}$ & 1987 \\
\hline & Floresta Estadual de Guarulhos ${ }^{2}$ & 2010 \\
\hline & $\begin{array}{l}\text { Área de Proteção Ambiental Cabuçu - Tanque } \\
\text { Grande }^{1}\end{array}$ & 2010 \\
\hline
\end{tabular}

Legenda: Municipal', Estadual ${ }^{2}$, Federal ${ }^{3}$

Quanto à distribuição espacial, verifica-se que elas formam um significativo mosaico de unidades de conservação concentrado na região norte do município e que, embora sejam autônomas, apresentam várias sobreposições.

Com respeito à cobertura do solo, observa-se que onde estão concentradas as unidades de conservação predomina uma paisagem rural. No entanto, podem ocorrer usos diversificados e tomados por espaços urbanos de forma muito variada, especialmente naquelas unidades de conservação pertencentes ao grupo de Uso Sustentável.

No contexto geomorfológico, de acordo com Ross e Moroz (1997), todas as unidades de conservação de Guarulhos, com exceção da Área de Preservação Ambiental (APA) da Várzea do Rio Tietê e uma pequena parte da APA Paraíba do Sul, encontram-se na região de abrangência do Planalto e da Serra da Mantiqueira. No caso da APA da Várzea do Rio Tietê, a geomorfologia corresponde a Pequenas Planícies Fluviais, já naquela porção da APA Paraíba do Sul à Bacia Sedimentar Cenozoica, ambas associadas ao Planalto de São Paulo. 


\section{Métodos}

Conforme o objetivo da pesquisa, o de se elaborar um índice de desempenho das UCs, foi realizada uma primeira avaliação do desempenho das condições das UCs de Guarulhos como estudo de caso. Como primeiro passo, foram considerados três fatores apenas relativos à fragilidade geoambiental, à quantidade da cobertura florestal nativa preservada e à implantação de instrumentos básicos de gestão. Esses três fatores foram equacionados na forma de um indicador sintético, o Índice de Desempenho das Unidades de Conservação (IDUC), que foi adaptado do Índice de Gestão das Unidades de Conservação utilizado pela Secretaria de Meio Ambiente do Estado de São Paulo (SMA, 2011), especificamente quanto aos parâmetros qualidade dos recursos protegidos e gestão.

O IDUC proposto para as UCs de Guarulhos (de zero a 10) foi equacionado da seguinte forma: fragilidade geoambiental (FG), com peso 1 (10\% da nota); grau de conservação com floresta nativa (GC), com peso 2 (20\% da nota); e nível de organização institucional (NO), com peso 7 (70\% da nota), através da seguinte fórmula de avaliação:

$$
I D U C=0,1 \times F G+0,2 \times G C+0,7 \times N O
$$

As análises foram efetuadas em ambiente de geoprocessamento (ArcGIS) proporcionado pelo laboratório do curso de Mestrado em Análise Geoambiental (MAG) da Universidade Guarulhos (UnG), onde foi montado um banco de dados espaciais a partir de dados políticos administrativos (limites municipais e bairros), limites das UCs, dados topográficos (curvas de nível, hidrografia e sistema viário), na forma de planos de informação obtidos da base de dados espaciais da Prefeitura Municipal de Guarulhos. Os dados de cobertura vegetal foram disponibilizados pelo acervo do MAG, com origem no projeto Bases Geoambientais de GuaruIhos (Oliveira et al., 2009).

As informações sobre a instituição dos instrumentos de gestão, conforme determina o SNUC, foram obtidas através de trabalhos de campo e consultas a técnicos envolvidos com a gestão ambiental em Guarulhos, no caso, a Secretaria Municipal de Meio Ambiente de Guarulhos e a Secretaria Estadual do Meio Ambiente de São Paulo. 


\section{Fragilidade Geoambiental (FG)}

A Fragilidade Geoambiental foi baseada na avaliação das unidades de relevo e índices geomorfológicos básicos como a declividade. Essa avaliação considera os pressupostos de Ross (1994) sobre a fragilidade potencial quanto aos processos de dinâmica superficial das encostas, entre eles, a erosão e a movimentação de massa, de forma que a declividade é o fator considerado em escalas de detalhe.

Foram gerados modelos digitais do terreno com o uso de dados topográficos da base cartográfica da Prefeitura Municipal de Guarulhos, na escala compatível a 1:25.000, e efetuadas estatísticas sobre a declividade de cada UC, de acordo com os limites de declividade propostos por Salomão (1999). Também foi quantificada, em cada UC, a abrangência das unidades de relevo definidas por Andrade (1999). Essa composição foi sintetizada no índice denominado Fragilidade Geoambiental (FG), cujo critério de avaliação basicamente consistiu no seguinte:

a) Sendo a declividade média da Unidade de Conservação $>30 \%$, a sua fragilidade geoambiental é classificada como ALTA. Havendo relevo serrano, a classificação passa a ser MUITO ALTA;

b) Se a declividade média está entre 20 e 30\%, a fragilidade geoambiental é classificada como MÉDIA. Havendo relevo serrano, a classificação passa a ser ALTA;

c) Quando a declividade média está abaixo de 20\%, a fragilidade geoambiental é classificada como BAIXA. Nesse caso, não ocorre relevo serrano associado.

Para efeito de cálculo do índice sintético final, foram atribuídas estas notas: 0,25 para a classe de fragilidade geoambiental BAIXA; 0,5 para a classe de fragilidade geoambiental MÉDIA; 0,75 para a classe de fragilidade geoambiental ALTA; e 1,0 para a classe de fragilidade geoambiental MUITO ALTA.

\section{Grau de Conservação (GC)}

O Grau de Conservação das UCs foi avaliado por meio da quantificação da cobertura florestal nativa obtida a partir do plano de informação 
do uso e da ocupação do solo de Oliveira et al. (2009) na escala compatível com 1:25.000.

Com base na superfície relativa com cobertura florestal nativa de cada UC, foram atribuídas notas da seguinte forma: 0,5 para a UC com até $25 \%$ de cobertura florestal; 1,0 para a UC contendo entre 25 e $50 \%$ de cobertura florestal; 1,5 para a UC contendo entre 50 e 75\%; e 2,0 para a UC com mais de $75 \%$ de cobertura florestal.

Nível de Organização Institucional (NO)

O critério assumido para a avaliação do Nível de Organização Institucional (NO) refere-se à implementação dos instrumentos principais previstos no SNUC, que são o plano de manejo e o conselho gestor. Conforme dispõe o artigo $2^{\circ}$, item XVII do SNUC, o plano de manejo é o "documento técnico mediante o qual, com fundamento nos objetivos gerais da unidade de conservação, se estabelece o seu zoneamento e as normas que devem presidir o uso da área e o manejo dos recursos naturais, inclusive a implantação das estruturas físicas necessárias à gestão da unidade”. O artigo 27 do SNUC determina claramente que as UCs devem dispor de um plano de manejo.

A obrigatoriedade das UCs de disporem de conselhos consultivos ou deliberativos é determinada pelo SNUC (artigos 15 para APA, 17 para Florestal Estadual e 29 para as UCs de proteção integral) e, especialmente, no seu regulamento dado pelo Decreto Federal 4.340/2002.

Dessa forma, o NO foi avaliado através da verificação da instalação dos conselhos gestores e planos de manejo das respectivas UCs. Para a UC com Conselho Gestor, foi conferida a nota 1,0 quando este é consultivo e nota 2,0, quando é deliberativo.

O plano de manejo é aqui considerado como o instrumento mais importante para a gestão das UCs. Por isso, foi conferida para as que possuem esse plano devidamente aprovado e implementado uma nota 5,0 que corresponde a 50\% da avaliação total do nível do IDUC.

Características das Unidades de Conservação no município de Guarulhos/SP

O panorama geral das UCs, em Guarulhos, revela que há sobreposição de áreas entre as suas diferentes categorias. Esse fato deve-se à criação 
de unidades de proteção integral que acabaram recobrindo áreas de unidades de uso sustentável e vice-versa.

O primeiro exemplo é o da APA Paraíba do Sul criada no ano de 1983 que, em 2010, foi parcialmente englobada pelo Parque Estadual do Itaberaba. Essa APA foi também sobreposta, no mesmo ano, por uma nova unidade de uso sustentável: a Floresta Estadual de Guarulhos.

O segundo caso é o da APA Cabuçu-Tanque Grande que foi criada pela Lei Municipal n. 6.798/2010, com um território que incluiu parte do Parque Estadual do Itaberaba, criado pelo Decreto Estadual n. 55.662/2010, e a totalidade do Parque Natural Municipal da Cultura Negra Sítio da Candinha, criado em 2008 pela Lei n. 6.475/2008, e a Estação Ecológica do Tanque Grande, criada pelo Decreto Municipal n. 28.273/2010.

Dessa forma, foi possível concluir que as UCs somadas recobrem cerca de $42 \%$ do território de Guarulhos. A Tabela 1 apresenta a consolidação destes resultados:

Tabela 1: Consolidação dos resultados de todas as UCs e respectivas abrangências em Guarulhos, descontadas as sobreposições.

\begin{tabular}{|l|c|c|}
\hline Espaços territoriais & $\begin{array}{c}\text { Área absoluta } \\
\text { (ha) }\end{array}$ & $\begin{array}{c}\text { Área relativa } \\
\text { (\%) }\end{array}$ \\
\hline Superfície total de Guarulhos & $31.919,46$ & 100 \\
\hline Superfície total das UCs de proteção integral & $9.116,91$ & 28,6 \\
\hline Superfície total das UCs de uso sustentável & $4.423,09$ & 13,9 \\
\hline Superfície total das UCs & $13.540,00$ & 42,4 \\
\hline
\end{tabular}

Considerando os perímetros originais de todas as Unidades de Conservação existentes, nota-se que ocorre uma sobreposição de 5.750,68 ha, ou seja, da superfície total da UC, 42,5\% são áreas sobrepostas de uso sustentável que estão hoje sob o regime de proteção integral.

As UCs de proteção integral possuem uma abrangência de 9.116,91 ha no território de Guarulhos. Na Tabela 2, pode-se observar a correspondência das superfícies de cada UC de proteção integral em relação ao município como um todo. 
Tabela 2: UCs de proteção integral e abrangência territorial no município de Guarulhos.

\begin{tabular}{|l|c|c|}
\hline Espaços territoriais & $\begin{array}{c}\text { Área de } \\
\text { abrangência } \\
\text { (ha) }\end{array}$ & $\begin{array}{c}\text { Área relativa } \\
\text { (\%) }\end{array}$ \\
\hline Superfície total de Guarulhos & $31.919,46$ & 100 \\
\hline Parque Estadual do Itaberaba (PEI) & $6.227,73$ & 19,5 \\
\hline Parque Estadual da Cantareira (PEC) & $2.674,15$ & 8,4 \\
\hline $\begin{array}{l}\text { Parque Natural Municipal da Cultura Negra } \\
\text { Sítio da Candinha (PNMCNSC) }\end{array}$ & 109,12 & 0,3 \\
\hline Estação Ecológica do Tanque Grande (EETG) & 86,30 & 0,3 \\
\hline Reserva Biológica Burle Marx (RBBM) & 19,61 & 0,1 \\
\hline Total & $9.116,91$ & 28,6 \\
\hline
\end{tabular}

Considerando a área total das UCs de proteção integral, em relação a cada uma delas, é possível perceber que há uma discrepância significativa entre aquelas criadas pelo governo do Estado de São Paulo e as demais de caráter municipal, uma vez que 97,6\% de toda a área relativa às UCs de proteção integral é estadual: Parque Estadual da Cantareira (PEC) e Parque Estadual do Itaberaba (PEI). Pela análise das UCs de uso sustentável em seus perímetros originais, ou seja, sem descontar a sobreposição com as de proteção integral, sabe-se que elas possuem uma abrangência de 10.173,77 ha no território de Guarulhos. Na Tabela 3, é possível observar a correspondência das superfícies de cada UC de uso sustentável em relação ao município como um todo:

Tabela 3: UCs de uso sustentável e abrangência territorial no município de Guarulhos.

\begin{tabular}{|l|c|c|}
\hline Espaços territoriais & $\begin{array}{c}\text { Área absoluta } \\
\text { (Ha) }\end{array}$ & $\begin{array}{c}\text { Área relativa } \\
\text { (\%) }\end{array}$ \\
\hline Superfície total de Guarulhos & $31.919,46$ & 100 \\
\hline $\begin{array}{l}\text { Área de Proteção Ambiental do Rio Paraíba } \\
\text { do Sul (APAPS) }\end{array}$ & $6.095,16$ & 19,1 \\
\hline $\begin{array}{l}\text { Área de Proteção Ambiental do Cabuçu- } \\
\text { Tanque Grande (APACTG) }\end{array}$ & 3223,37 & 10,1 \\
\hline $\begin{array}{l}\text { Área de Proteção Ambiental da Várzea do } \\
\text { Rio Tietê (APAVT) }\end{array}$ & 763,03 & 2,4 \\
\hline Floresta Estadual de Guarulhos (FEG) & 92,21 & 0,3 \\
\hline Total & $10.173,77$ & 31,9 \\
\hline
\end{tabular}


Considerando a área total das UCs de uso sustentável, em relação a cada uma delas, é possível perceber que apenas a APA do Paraíba do Sul representa quase $60 \%$ de toda a superfície de UCs de uso sustentável.

Fragilidade Geoambiental (FG)

A análise da fragilidade geoambiental das UCs permitiu classificá-las em níveis diferenciados apresentados no Quadro 2:

Quadro 2: Classificação da fragilidade geoambiental da UC de Guarulhos.

\begin{tabular}{|cccc|}
\hline $\begin{array}{c}\text { Classe de } \\
\text { fragilidade }\end{array}$ & $\begin{array}{c}\text { UC de } \\
\text { Guarulhos }\end{array}$ & $\begin{array}{c}\text { Declividade média } \\
\text { (\%) }\end{array}$ & $\begin{array}{c}\text { Proporção com } \\
\text { relevo serrano (\%) }\end{array}$ \\
\hline \multirow{2}{*}{ Muito } & PEC & 32,05 & 18,9 \\
Alta & PEI & 32,03 & 15,5 \\
& APAPS & 31,63 & 16,3 \\
& APAVT* & ------ & ----- \\
\hline \multirow{2}{*}{ Alta } & PNMCNSC & 33,55 & -- \\
& FEG & 31,73 & -- \\
\hline Média & APACTG & 23,27 & 2,5 \\
\hline Baixa & EETG & 28,28 & --- \\
\hline
\end{tabular}

${ }^{*}$ A APAVT é enquadrada nesta classificação por outros fatores.

Vale destacar que, no caso da APA da Várzea do Rio Tietê, prevalece uma dinâmica geoambiental diferenciada, pois se trata de uma área de planície aluvionar sujeita a processos deposicionais. Assim, essa UC também foi considerada com fragilidade geoambiental MUITO ALTA, pelos processos de assoreamento e pela contaminação hídrica.

Grau de Conservação (GC)

A cobertura florestal nativa das UCs de proteção integral totaliza $8.202,07$ ha de florestas preservadas. A quantidade de floresta de cada uma delas, com base no levantamento da cobertura do solo (Oliveira et al., 2009), é apresentada na Tabela 4. 
Tabela 4: Quantidade de cobertura florestal das UCs de proteção integral em Guarulhos.

\begin{tabular}{|l|c|c|}
\hline Unidade de Conservação de Proteção Integral & $\begin{array}{c}\text { Área de } \\
\text { floresta (Ha) }\end{array}$ & $\begin{array}{c}\text { Área relativa } \\
\text { (\%) }\end{array}$ \\
\hline Parque Estadual do Itaberaba (PEI) & $5.424,11$ & 66,1 \\
\hline Parque Estadual da Cantareira (PEC) & 2.624 & 32 \\
\hline $\begin{array}{l}\text { Parque Natural Municipal da Cultura Negra } \\
\text { Sítio da Candinha (PNMCNSC) }\end{array}$ & 79,79 & 1 \\
\hline Estação Ecológica do Tanque Grande (EETG) & 62,32 & 0,8 \\
\hline Reserva Biológica Burle Marx (RBBM) & 11,85 & 0,1 \\
\hline Total & $8.202,07$ & 100 \\
\hline
\end{tabular}

A avaliação da quantidade de cobertura florestal das UCs de uso sustentável corresponde a um total de 6.580,68 ha de florestas preservadas nessas UCs. A quantidade de floresta de cada uma delas, com base no levantamento da cobertura do solo (Oliveira et al., 2009), é apresentada na Tabela 5:

Tabela 5: Quantidade de cobertura florestal das UCs de uso sustentável em Guarulhos.

\begin{tabular}{|l|c|c|}
\hline Unidade de Conservação de Uso Sustentável & $\begin{array}{c}\text { Área de } \\
\text { floresta (Ha) }\end{array}$ & $\begin{array}{c}\text { Área relativa } \\
\text { (\%) }\end{array}$ \\
\hline $\begin{array}{l}\text { Área de Proteção Ambiental do Rio Paraíba do } \\
\text { Sul (APAPS) }\end{array}$ & $4.994,84$ & 75,9 \\
\hline $\begin{array}{l}\text { Área de Proteção Ambiental do Cabuçu- } \\
\text { Tanque Grande (APACTG) }\end{array}$ & $1.471,36$ & 22,4 \\
\hline Floresta Estadual de Guarulhos (FEG) & 74,79 & 1,1 \\
\hline $\begin{array}{l}\text { Área de Proteção Ambiental da Várzea do Rio } \\
\text { Tietê (APAVT) }\end{array}$ & 39,69 & 0,6 \\
\hline Total & $6.580,68$ & 100 \\
\hline
\end{tabular}

Índice de Desempenho das Unidades de Conservação (IDUC) de Guarulhos

A partir das avaliações antecedentes, foi calculado o IDUC de Guarulhos. A Tabela 6 apresenta de forma sistematizada o resultado desta avaliação efetuada de forma qualitativa para as UCs de proteção integral e a Tabela 7 para as UCs de uso sustentável. 
Tabela 6: Avaliação do IDUC de proteção integral de Guarulhos.

\begin{tabular}{|l|c|c|c|c|}
\hline $\begin{array}{c}\text { Unidade de } \\
\text { Conservação }\end{array}$ & $\begin{array}{c}\text { Fragilidade } \\
\text { Natural (FN) }\end{array}$ & $\begin{array}{c}\text { Grau de } \\
\text { Conservação } \\
\text { (GC) }\end{array}$ & $\begin{array}{c}\text { Organização } \\
\text { Institucional } \\
\text { (No) }\end{array}$ & IDUC \\
\hline PE Cantareira & 1 & 1 & 6 & 9 \\
\hline PNMCNS Candinha & 0,75 & 1,5 & 0 & 3,25 \\
\hline PE Itaberaba & 1 & 2 & 0 & 3 \\
\hline EE Tanque Grande & 0,5 & 1,5 & 0 & 2 \\
\hline RB Burle Marx & 0,25 & 1,5 & 0 & 1,75 \\
\hline
\end{tabular}

Tabela 7: Avaliação do IDUC de uso sustentável de Guarulhos.

\begin{tabular}{|l|c|c|c|c|}
\hline \multicolumn{1}{|c|}{$\begin{array}{c}\text { Unidade de } \\
\text { Conservação }\end{array}$} & $\begin{array}{c}\text { Fragilidade } \\
\text { Natural }\end{array}$ & $\begin{array}{c}\text { Grau de } \\
\text { Conservação }\end{array}$ & $\begin{array}{c}\text { Organização } \\
\text { Institucional }\end{array}$ & IDUC \\
\hline $\begin{array}{l}\text { APA Cabuçu- } \\
\text { Tanque Grande }\end{array}$ & 0,75 & 1 & 2 & 3,75 \\
\hline $\begin{array}{l}\text { APA Várzea do Rio } \\
\text { Tietê }\end{array}$ & 1 & 0,5 & 2 & 3,5 \\
\hline APA Paraíba do Sul & 1 & 2 & 0 & 3 \\
\hline FE Guarulhos & 0,75 & 2 & 0 & 2,75 \\
\hline
\end{tabular}

Os resultados demonstram que a UC de proteção integral com melhor qualidade na gestão ambiental corresponde ao Parque Estadual da Cantareira. O índice de gestão do PEC não atingiu nota máxima simplesmente porque não possui conselho gestor deliberativo, fato esse que pode ser alterado a qualquer momento pelo órgão responsável pela gestão da respectiva UC.

Com relação às UCs de uso sustentável, a APA do Cabuçu-Tanque Grande destaca-se e ganha melhor posição do que a APA da Várzea do Rio Tietê, pelo fato de essa última ter baixo grau de conservação. A ausência dos planos de manejo em ambas as UCs, nesse caso, foi significativa para que as notas atribuídas tivessem valores bem baixos.

De forma geral, conclui-se que existem apenas quatro conselhos atuantes: Conselho do Parque Estadual da Cantareira (PEC); da Área de Proteção Ambiental Várzea do Tietê (APAVT); da Área de Proteção Ambiental Cabuçu Tanque-Grande (APACTG) e do Parque Natural Municipal da Cultura Negra Sítio da Candinha (PNMCNSC). Insta, ainda, destacar que a única unidade de conservação com plano de manejo efetivado até o momento é o Parque Estadual da Cantareira (PEC). 


\section{Considerações finais}

O município de Guarulhos, apesar da influência exercida pela enorme expansão urbana, possui, inseridas em seu território, nove unidades de conservação da natureza federais, estaduais e municipais, pertencentes às seguintes categorias: Estação Ecológica, Reserva Biológica, Parque, Área de Proteção Ambiental e Floresta Estadual, cujas definições encontram-se, respectivamente, nos artigos $9^{\circ}, 10,11,15$ e 17 da Lei n. $9.985 / 2000$.

Nesse contexto, Guarulhos é um lugar especial por conter inúmeras áreas naturais protegidas, pois constata-se, neste estudo, que aproximadamente $42 \%$ de seu território, descontadas as sobreposições, especialmente na região norte, está constituído por Unidades de Conservação, ou seja, quase a metade do território total do município.

O parque da Cantareira, do Itaberaba e o da Cultura Negra Sítio da Candinha, a APA do Paraíba do Sul e a do Cabuçu-Tanque Grande e a Estação Ecológica Tanque Grande estão associadas à região norte de Guarulhos e com o corredor ecológico da Mantiqueira; cada uma dessas áreas apresenta uma função primordial no mosaico de conservação da Cantareira. Além de extremamente necessárias pela contribuição ao equilíbrio ecológico urbano, pela regulação térmica e de prevenção de processos geo-hidrológicos, provisão de água e da qualidade do ar, vale ressaltar que essas áreas também podem ser geradoras de emprego, renda, lazer e de outros benefícios sociais ao município.

O Parque Estadual da Cantareira e o Parque Estadual de Itaberaba representam 98\% da cobertura florestal das UCs de proteção integral. Já a APA do Paraíba do Sul e a do Cabuçu-Tanque Grande representam igualmente 98\% da cobertura florestal das UCs de uso sustentável. Assim, essas UCs podem ser consideradas as mais importantes sob o ponto de vista da conservação florestal.

De forma geral, considerando os dois grupos determinados pelos artigos $8^{\circ}$ e 14 da Lei n. 9.985/2000, existem apenas três conselhos atuantes: Conselho do Parque Estadual da Cantareira (PEC); da Área de Proteção Ambiental Várzea do Tietê (APAVT); e da Área de Proteção Ambiental Cabuçu-Tanque Grande (APACTG). Dessa forma, como as unidades de conservação de Guarulhos formam um mosaico de unidades, em âmbito federal, estadual e municipal, e que apenas 1/3 dessas áreas possuem conselho gestor, um grande desafio que se revela para a gestão dessas unida- 
des de conservação é a instituição de um conselho de mosaico integrado à Reserva da Biosfera do Cinturão Verde da Cidade de São Paulo (RBCV), em cumprimento ao artigo $9^{\circ}$ da Lei n. 9.985/2000. Isso facilitaria a gestão integrada das áreas sobrepostas, com o estabelecimento de regras claras e bem definidas para evitar futuros conflitos de competência.

Por fim, constata-se que, apesar de todo o esforço na gestão das duas APAs (APAVT e APACTG) e dos dois Parques (PEC e PNMCNSC), as ações do Poder Público Estadual e Municipal, no gerenciamento das unidades de conservação inseridas em Guarulhos/SP, ainda precisam avançar para atingir os objetivos motivadores de sua criação, posto que os efetivos ganhos socioambientais das UCs só acontecem com contínuos esforços. O ato de criar é apenas o fator que abre esta oportunidade.

\section{Referências}

ANDRADE, M. R. M. Cartografia de aptidão para assentamento urbano do município de Guarulhos/SP. Dissertação (Mestrado em Geografia) - FFLCH, USP, São Paulo, 1999. 154p.

BRASIL. Sistema Nacional das Unidades de Conservação da Natureza. Lei n. 9.985 de 18 de julho de 2000.

IBGE. Instituto Brasileiro de Geografia e Estatística. Dados socioeconômicos de 2009. Disponível em: <http//www.ibge.gov.br>. Acesso em: 20 jan. 2012.

IBGE. Instituto Brasileiro de Geografia e Estatística. Censo demográfico de 2010. Disponível em: <http//www.ibge.gov.br>. Acesso em: 20 jan. 2012.

OLIVEIRA, A. M. S.; ANDRADE, M. R. M.; SATO, S. E; QUEIROZ, W. Bases geoambientais para um sistema de informações ambientais do município de Guarulhos. Guarulhos: Laboratório de Geoprocessamento. Universidade Guarulhos (Relatório Fapesp), 196 p., 2 v., Mapas. 2009.

RODRIGUES, E. A; VICTOR, R. A. B. M; PIRES, B. C. C. A reserva da biosfera do cinturão verde na cidade de São Paulo como marco para a gestão integrada da cidade, seus serviços ambientais e o bem-estar humano. São Paulo em Perspectiva, São Paulo: Fundação SEADE, v.20, n.2, p.71-89, 2006.

ROSS, J. L. S. Análise empírica da fragilidade dos ambientes naturais e antropizados. Revista do Departamento de Geografia/FFLCH/USP, n. 8, p. 63-73, 1994.

ROSS, J. S.; MOROZ, I. C. Mapa geomorfológico do Estado de São Paulo. São Paulo: FFLCH-USP/Laboratório de Cartografia Geotécnica-Geologia Aplicada-IPT/Fapesp-Fundação de Amparo à Pesquisa do Estado de São Paulo, 64 p. 1997.

SALOMÃO, F. X. T. Controle e prevenção dos processos erosivos. In: GUERRA, A. J. T.; SILVA, A. S.; BOTELHO, R. G. M. Erosão e conservação dos solos. Rio de Janeiro: Bertrand Brasil, 1999. p. 229-267. 
SECRETARIA DO MEIO AMBIENTE/COORDENADORIA DE PLANEJAMENTO AMBIENTAL. Painel da qualidade ambiental. São Paulo: SMA/CPLA, 2011. 132 p.

Silmara Guerra Ferraz da Fonseca - Possui Mestrado em Análise Geoambiental pela Universidade Guarulhos e é Especialista em Direito Ambiental e Bioética pela Universidade de São Paulo. Atualmente é professora na Universidade Guarulhos.

Marcio Roberto Magalhães de Andrade - Possui Graduação em Geologia pela Universidade de São Paulo, Mestrado e Doutorado em Geografia pela mesma Universidade. Atualmente é professor da Universidade Guarulhos.

Antonio Manoel dos Santos Oliveira - Possui Graduação em Geologia pela Universidade de São Paulo, Mestrado em Geociências e Doutorado em Geografia pela mesma Universidade. Atualmente é professor na Universidade Guarulhos.

Recebido para publicação em 9 de novembro de 2013 Aceito para publicação em 3 de fevereiro de 2014 